\title{
Local Authorities' Views and Attitudes on Sustainable Energy Policy: The Case of Mayors of Rhodes, Island, Greece (2010-2014)
}

\author{
Anastasia Dimitriou', Dimitris Pimenidis ${ }^{2}$ \\ ${ }^{1}$ Department of Education Sciences in Early Childhood, School of Education Sciences, Laboratory of Research and Communication for the \\ Environment and Environmental Education, Democritus University of Thrace, Alexandroupolis, Greece \\ ${ }^{2}$ Department of Pre-school education and Design, School of Humanities, Msc Environmental Education, University of Aegean, Rhodes, Greece \\ Email address: \\ anadim@otenet.gr (A. Dimitriou), poimenidis@aegean.gr (D. Pimenidis)
}

\section{To cite this article:}

Anastasia Dimitriou, Dimitris Pimenidis. Local Authorities' Views and Attitudes on Sustainable Energy Policy: The Case of Mayors of Rhodes, Island, Greece (2010-2014). International Journal of Environmental Protection and Policy. Vol. 3, No. 2, 2015, pp. 20-30.

doi: $10.11648 /$ j.ijepp.20150302.11

\begin{abstract}
To create effective climate change mitigation energy policies that contribute to greenhouse gases reduction are required. To this direction, local authorities play a crucial role as they are responsible for the planning and implementation of energy policies in their territories. This study aims to investigate the local authorities' knowledge and attitudes on energy production, energy management, energy consumption and renewable energy sources (RES), as well as their energy practices and their intentions. The study was carried out in the island of Rhodes, Greece where 12 elective representatives of local authorities (municipalities and prefecture) were asked to fill in a questionnaire on the above issues. Almost all of the participants recognized energy saving as an important dimension of energy policy. They indicated their intentions for energy saving applications in the future, but the measures they use to apply in their area of responsibility are extremely limited. Despite respondents' positive attitudes towards the use of RES, they seem to hesitate to develop an energy model based mainly on RES, as they believe they cannot cover the energy needs of the island. They also, believe that they play a secondary role in the planning and development of energy policy at a local level, as they estimate that energy policy is mainly a matter of the central government. Findings show that there is a demand for a more specialized and focused energy policy. They further show the need for specialized environmental education programs addressed to local authorities aiming at increasing motivation as well as supporting their efforts for the implementation of sustainable energy policies.
\end{abstract}

Keywords: Local Authorities, Mayors, Attitudes, Views, Energy Policy, Sustainability

\section{Introduction}

Energy issue is one of the most important environmental issues as it is closely connected to a large number of serious environmental problems. Production and consumption of energy result air pollutants emissions that reinforce greenhouse effect with consequence climate change. These air pollutants are known as greenhouse gases (carbon dioxide, methane, nitrous oxide and fluorinated gases are the most important). These gases absorb and emit radiation within the thermal infrared range. This process is the fundamental cause of the greenhouse effect and climate change as well [1].

Taking measures against climate change is one of the outstanding aims of European Union, in the frame of which are formed energy strategies for the reducing of greenhouse gas emission. For the achievement of this aim, improvements in the field of energy policy are required because the use of energy contributed up to $80 \%$ of the greenhouse air pollutants. Actions such as the more rationally use of energy, energy saving, the implementation of renewable energy sources in the generation of electricity and other energy needs, are recognized as very important [2-4].

In this context, the role of local authorities is recognized as crucial, because they are responsible for the planning and implementation of energy policies; they shape citizens' environmental attitudes as well as public opinion on environmental issues and they also raising citizens active participation for confronting environmental problems. Local authorities are also significant energy consumers through their operations in services, in heating, cooling and lighting of 
public buildings (schools, hospitals, and offices) and street lighting as well.

European Commission has a crucial role to play in helping local and regional authorities to form sustainable energy policy and supporting their efforts to implement. Its decisive contribution reflects in the development of the 'Covenant of Mayors':

The Covenant of Mayors is the mainstream European movement involving local and regional authorities, voluntarily committing to increasing energy efficiency and use of renewable energy sources on their territories. By their commitment, Covenant signatories aim to meet and exceed the European Union $20 \% \mathrm{CO}_{2}$ reduction objective by 2020 [5].

In Greece, to date, 89 Municipalities are participated in this movement, among which 11 island municipalities [6], that is very limited number given the total number of Greek municipalities comes up to 325 [7].

Local authorities have a leading role in the function of their communities. According to the national legislation local authorities in Greece, take responsibilities which permit them the planning and implementation policies for the environment, the development and the quality of life.

Given the environmental problems facing modern societies and the necessity to implement measures for their confrontation in the perspective of sustainability, the issue is the policies which implement in local level to immunize environmental quality and sustainable development. Local authorities' role for the achievement of sustainable development is vital while:

Local authorities construct, operate and maintain economic, social and environmental infrastructure, oversee planning processes, establish local environmental policies and regulations, and assist in implementing national and sub national environmental policies. As the level of governance closest to the people, they play a vital role in educating, mobilizing and responding to the public to promote sustainable development [8].

A crucial question is whether local authorities' representatives, as policy makers, make their decisions in an environmental responsible way that contributes towards environmental preservation and protection. In other words, the issue is whether the policy makers act as environmental responsible citizens; as citizens with awareness, environmental knowledge and interest to understand the environmental problems and with the intention and the capability to solve them [9-10].

One of the most important contemporary environmental issues come under the responsibility of local authority is the energy management. Therefore, mayors' conceptions of energy issue and their attitudes towards energy management are key factors for implementing energy policy ensuring environmental quality and sustainable development.

While research has extensively studied citizens', educators' and pupils' conceptions of energy issues, [11-16] only a small number of relevant studies have focused on local authorities. In particular, Mayors' conceptions of energy issues and attitudes towards energy policies are scarce [17-18]. Other studies, however, have recorded the influence of local authorities in energy governance but do not focuses on mayor's conceptions and attitudes towards energy issues [19].

The above mentioned suggest the importance of investigating the mayor's conceptions and attitudes towards the production, management and consumption of energy, as well as the degree of implementation of RES technologies and technological solutions at a local level.

This research aims to explore the knowledge and attitudes of the elected representatives of local and regional authorities of Rhodes, Greece, towards the production, management and consumption of energy and RES; and the degree of implementation of energy technologies and technological solutions at a local level. In particularly, the research aims to investigate: a) the knowledge of the participants about energy issue, b) determine the extent to which they implement sustainable energy policy, c) their attitudes towards the implementation of measures for the rationale use and energy saving, d) determine the extent to which they understand the use of RES in confronting energy problem and their attitudes towards RES, e) the measures they take or they tent to confront the energy problem. Additional, the level of their environmental awareness and the kind of the resources they use for their information, are investigated. Findings of this research may show several dimensions of energy issues that may exploit to supporting the efforts of local and regional authorities for the implementation of sustainable energy policies, and for the planning and development of educational programs concerning energy issues. The results of this study are presented and discussed in the present paper.

\section{Energy Policy and Sustainability}

\subsection{Energy Policy Towards Sustainability}

The energy model of contemporary societies seems not to promote sustainable development and this, because it is connected with the overconsumption of energy, the exhaustion of natural resources, environmental degradation and climate change. In addition, political crisis between countries that produce and provide energy might lead to energy crisis in the countries which import energy. These conditions make it more and more important to implement sustainable energy policies at local and regional level. Due to the environmental problems connected with energy production and consumption, there has been an urge to change the model of energy production, which is currently based on fossil fuels (oil, lignite). The development of a sustainable energy model should definitely involve the use of renewable energy sources (RES), as they mainly contribute to climate change mitigation through the reduction of greenhouse gas emissions. Renewable energy sources continue renew by the cycle of nature and are never exhausted such as sun, wind, rivers, oceans and organic 
materials. Solar, wind, geothermal, bioenergy and hydropower, are considered to be important RES that contribute to the reduction of greenhouse gas [20 -22].

The greatest challenge for the planners of energy policy is the design, the development and the management of appropriate, economically affordable and reliable energy services in a sustainable way, in order to reinforce and support sustainable development $[3,22]$. The implementation of renewable energy technologies, as well as, actions for energy saving, and improvement of energy efficiency contribute to a sustainable energy future $[4,22]$. To this direction, the European energy policy is being formed mainly aiming at energy saving, the use of RES and the reduction of greenhouse gases emissions. For the application of this energy policy several national action plans have been designed which Member States are asked to implement $[2,24]$. In particular, for the total of Member States, until 2020, main targets are as follows: a) reduce of greenhouse gas by at least $20 \%$ compared to 1990 levels, b) increase the share of RES in final energy consumption and c) an a $20 \%$ increase in energy efficiency [2, 24].

For Greece, the protection of climate through the promotion of electrical energy from RES constitutes an environmental and energy priority of the highest importance. The main national target, is the reduction of greenhouse gases by $4 \%$ by the end of 2020 , in relation to 2005 levels, and achieves an $18 \%$ RES infiltration into gross final consumption. To this direction, the national energy policy for RES, aims at: a) contribution of energy produce from RES to the gross final energy consumption by a share of $20 \%$ and b) contribution of electrical energy produce by RES to the gross energy consumption to a share of at least $40 \%$ [25]. Energy needs are expected to be met with the production of approximately $13300 \mathrm{MW}$ electricity from RES (currently producing $4000 \mathrm{MW}$ ) with the contribution of the available renewable energy technologies $(7500 \mathrm{MW}$ from wind fans, 3000MW from hydro-electric plants and 2500MW from solar systems) as well as the improvement of buildings energy efficiency [25].

\subsection{Area of Study and Energy Situation}

The island of Rhodes is located in the prefecture of the Dodecanese, in the south-east of Athens and it is the fourth largest island of Greece with a population of 115.290 (figure 1). Rhodes Island is one of the most popular touristic destinations, especially in summer period. Over than 2.000.000 people visit Rhodes annually that means that its population increase dramatically. As a result, Rhodes faces an increased energy demands that, in turn, pressure the operation of the electricity productive units pushing them onto borderline levels [26].

A steam-electric power plant situated in Soroni, at the South of the island, about $23 \mathrm{~km}$ from the city of Rhodes, is the basic electric production unit in the island. The steam-electric power plant of Soroni is an independent and non-interconnected energy production system, which autonomously produces electrical energy for Rhodes and the neighboring island of Halki (figure 1).
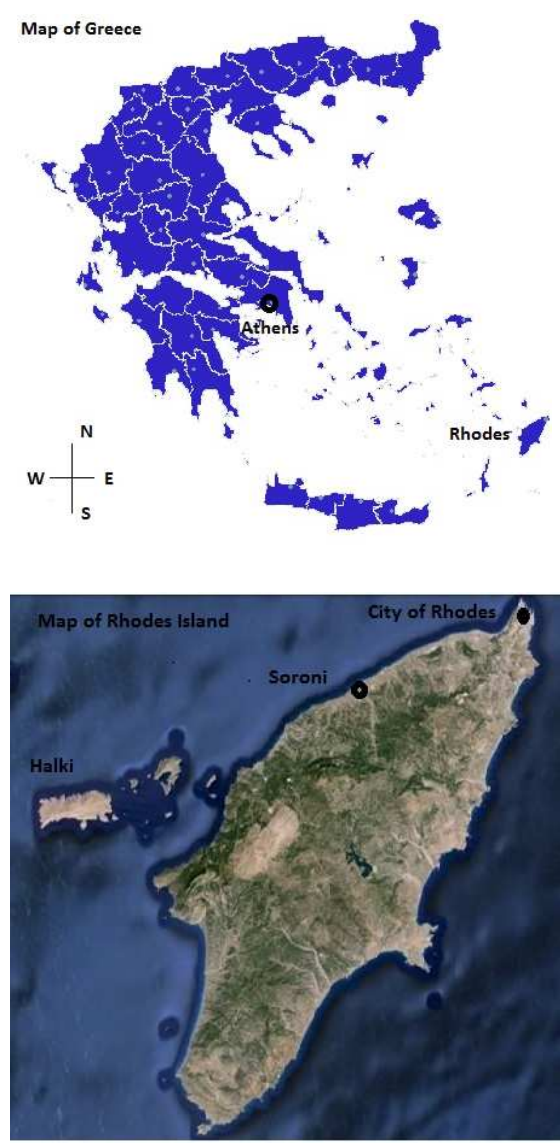

Figure 1. The area of study

The electric power plant operates by the use of crude oil and diesel that are transported by tankers. Fuels via undersea and underground pipelines are transported from the tanker to tanks situated in the area of the plant.

During last decades, it is observed a huge growth in the amounts of electrical energy consumption in Rhodes. Particularly, in 1995 the total electrical energy consumption was about 393.205 MWh. In 2010, it almost duplicated, reaching up to 764.593 MWh. During the years 2010-2014 the average annually electrical energy consumption was about 780.000 MWh [26-29].

The installed capacity of Rhodes power plant is currently 206 MW. Its marginally covers the amounts of electrical energy required especially during summer, because of the increasing touristic activity. Official data state as maximum power demand for 2012 being $202 \mathrm{MW}$ and for 2013 as high as $210 \mathrm{MW}$ [27-29].

In the recent years, since 2008, RES systems have been installed to support the local electrical energy production. The RES systems included wind generators and photovoltaic systems with installed capacity 49,15 MW and 16,92 MW respectively. These RES systems are owned by individuals-investors, except wind generators of 4.95 MW owned by the Public Power Corporation, of Greece [29]. The contribution of the electrical energy produce by RES seems to increase during last years. Especially, in 2010 up to $7.43 \%$ of the total electrical energy production was coming from RES technologies $(7.18 \%$ and $0.25 \%$ of wind and solar energy 
respectively) [26-28]. By the end of 2013, the contribution of RES into the local electric power system was increased reaching up to $15.5 \%$ of the total energy production while by the end of the year before was $9.8 \%[27,29]$. During the year 2014 , the inflow of energy from RES into the local system reached up to $17.6 \%$ of the total energy production [30].

As official data recorded, for the production of approximately 298.070 MWh from the steam-electric power station of Rhodes, 65.665 metric tons of crude oil and 10.723 Klit of diesel were used. Data, also estimated that carbon dioxide emissions reached up to 221.965,942 metric tons [30].

From the above it is clear that the electrical energy consumption in Rhodes Island increase over the years, mainly due to touristic activity. The existing electrical power plant seems no to respond to the required electrical energy demands. Thus, the issue is the planning and implementation of energy policy that ensure energy efficiency in a sustainable way.

It is astonishing that, despite the national action plan for the development of sustainable energy policy, at this time, it is scheduled the construction of one additional steam-electric plant station in Rhodes to support the existing one. The construction of a new conventional power plant in Soroni or in another area of the island triggers serious controversy between local community authorities and the residents of Rhodes, who demand an energy model towards environmental sustainability [31].

\section{Methodology}

\subsection{Participants}

The participants were twelve (12), elected representatives of local and regional authorities of Rhodes, Greece, for the period 2010-2014. Ten (10) of them were mayors of equal in number municipalities, and two (2) were representatives of Regional authority. Until 2014, there were 10 municipalities in Rhodes. Today, (2015) after the new administrative division that occurs in Greece, there is one union municipally in the island of Rhodes that consists of 10 municipal units, similar to the municipalities of the period 2010-2014. At this time (2015) the majority of the participants are also elected representatives of the new municipal units.

All participants are married and almost all of them are parents (11/12). Researchers communicated with the participants at a personal level for investigating their wiliness to participate in the survey. Participants were told the aim of the survey and that the survey results would be published. Participation in the study was voluntary and anonymous, and participants were also told that if they did not wish to participate they could simply not answer the questionnaire. Participants were asked to answer the questions during a face-to face interviews.

\subsection{Instrument}

For the purpose of the study, a questionnaire was designed by the authors that consisted of open and closed questions. The questionnaire aims to elicit information about mayors' views and attitudes regarding energy policy in a sustainable way. The questionnaire apart from the initial questions concerning participant's demographic characteristics consisted of four parts. In the first part the respondents were asked to estimate the level of their environmental awareness, their sources of environmental information, the degree of their knowledge and education on environmental issues and problems. The second part of the questionnaire consisted of open and closed questions (multiple-choice and Linker type) concerning the knowledge and beliefs of the respondents regarding the ways of production and use of electric energy, the forms of RES and their contribution to the energy production locally and nationally; the level of the application of RES technologies in energy production. In the third part of the questionnaire the respondents were asked to answer questions regarding RES and the extent to which RES technologies use in their municipality and the way they use them; as well as their attitudes towards RES. The forth part of the questionnaire focuses on the conceptions of the participants of the designing of energy policy including RES, the existing way of using and implementing measures towards energy saving in their municipalities, issues concerning personnel education on energy management and the possible existence of factors affecting their attempt to establish sustainable energy policy.

For developing and testing the adequacy of the questionnaire, a pilot study was conducted for overcoming any misunderstandings and assessing whether the research protocol is realistic and workable.

\section{Results}

\subsection{Participant's Demographic Characteristics, Environmental Awareness}

All participants are male that reflects the situation of the limited number of female mayors in Greece; and in terms of age are divided equally into two age group, 30-45 and 46-60 years old. Their educational level is very high, while the majority had graduated studies. During their studies, almost half of the respondents received education on environmental issues in contrast to the majority who state that they have not received relevant education (Table 1).

Table 1. The participants' demographic characteristics

\begin{tabular}{ll}
\hline Characteristics & Frequency (f) \\
\hline Gender & 12 \\
Male & 12 \\
Female & 0 \\
Age & \\
$30-45$ & 6 \\
$46-60$ & 6 \\
Level of Education & \\
Higher & 10 \\
Secondary & 2 \\
Education on environmental issues & \\
Yes & 5 \\
No & 7 \\
\hline
\end{tabular}


The majority of the respondents (10/12) regard themselves as well-informed about the environment and related issues while two of them $(2 / 12)$ say that they feel moderate informed; as they say, they receive environmental information very often and often respectively. Respondents were given a list of several information sources and were asked to identify their main sources of information about environmental issues (Table 2). Television, press, internet and local government environmental bodies are the most important information source for almost all the participants. Few of the mayors cite professional associations or research-training institutes at University level as one of their main information sources.

Table 2. Participants' environmental information sources

\begin{tabular}{ll}
\hline Sources & Frequency (f) \\
\hline Television & 11 \\
Press & 11 \\
Internet & 11 \\
Local government environmental bodies & 11 \\
Professional associations & 8 \\
Research-training institutes & 2 \\
\hline
\end{tabular}

When the participants were asked to consider how important protecting environment is to them personally, all of them cite that is very important.

Overall, the majority of the respondents consider as most pressure contemporary environmental problems facing in Greece those are connected with the energy issue. Specifically, the energy production, the energy adequacy and the exhaustion of natural resources seems to be the most pressure environmental problems for the majority of the respondents (Table 3).

Table 3. Participants' views about most pressure environmental problems in Greece

\begin{tabular}{ll}
\hline Environmental problems & Frequency (f) \\
\hline Energy production & 10 \\
Energy adequacy & 10 \\
Exhaustion of natural resources & 10 \\
Ecosystems degradation & 10 \\
Global warming & 9 \\
Acid rain & 9 \\
Water pollution & 9 \\
Use of toxic substances & 2 \\
Depletion of ozone layer & 2 \\
Urbanization & 2 \\
\hline
\end{tabular}

\subsection{Knowledge Concerning Energy Issue and RES}

For the purposes of the recording of the participants' knowledge on energy issues certain questions were formed related to the sources of energy production both at a national and local level, the forms of RES and the technologies applied for their utilization, the sufficiency of the existing power plant and its potential extension, the building of an additional one and the use of RES for the energy needs of the island and the most important domains of energy consumption. From the answers analysis it is clear that the majority of the respondents are highly informed on the ways of energy production both at a national and a local level. They refer to the burning of lignite and the use of oil as exclusive sources of energy production nationally and locally respectively. It is worth pointing out that three of the participants refer to lignite burning as a means of energy production locally, which is not applied. The RES are referred to by all the participants as sources partially applied nationally and locally.

Specifically, regarding RES forms used for energy production respondents focus on solar and wind power. Almost everybody (10 out of 12) is aware of the simultaneous existence of energy production systems, which at a local level involve a combination of solar and wind power. As to the ownership of RES on the island almost all locally elected representatives (11 out of 12) know that it is primarily private, while only one refers to mixed ownership, that is a partnership between private investors and public bodies, a situation that exists in Rhodes, as already mentioned, a partnership between Public Power Corporation and individuals.

In respect with the domains of large energy consumption, nearly all of the respondents refer to the hotel industry (11 out of 12). Instead, local authorities are considered a large energy consumer only by half of the participants (6 out of 12 ).

From the analysis of the answers given by participants concerning the energy production system on the island it seems that all of them agree with the fact that the existing system is insufficient. Nearly everyone (11 out of 12) seems to believe that apart from the existing power plant there is a need for a second one in the same area (Southern Rhodes) and a simultaneous broad application of RES. The closing down of the existing power plant and the building of a new more powerful one with the simultaneous energy production with the use of RES is an idea that most of the participants agree upon (10 out of twelve). Only two of the respondents seem to agree with the closing down of the existing system and the exclusive production of energy through RES. The rest are completely negative.

Regarding the degree to which the participants appreciate the information they receive on energy saving issues, the rational use of energy and the RES applications there are variations. In particular, the majority of the participants ( 9 out of 12) estimate that they are adequately informed on energy saving issues, fewer believe the same about issues related to RES applications (7 out of twelve) and even fewer (6 out of 12) about issues concerning the rational use of energy. As far as the above issues are concerned, basic sources of information for the majority of the participants are the web (11 out of 12) and the press (9 out of 12), while for half of them (6 out of 12) are relevant workshops or seminars organized by universities and institutes.

\subsection{Views and Attitudes on RES}

From the answers given it seems that most of the respondents (9 out of 12) do not believe that RES can exclusively meet the energy needs of the island. Only a small minority (3 out of 12) absolutely believe in such a possibility.

Investigating the attitude towards energy production exclusively with the use of RES, in case this is practically feasible, it seems that almost all of the participants are positive. 
However, it is evident that most of them (7 out of 12) would opt for RES for the production of energy, on the condition that the cost would not exceed the current one of conventional energy production (use of oil). What is worth mentioning is that one out of three (4 out of 12) is willing to choose exclusively the use of RES for energy production affording even a double cost, while only one would afford a triple cost. The choice of RES as an exclusive means of energy production would be desirable by everyone, as they believe that RES are environmentally friendly and their use reduces greenhouse gases emissions, nevertheless they think they are ineffective.

The participants were asked to refer to the forms of RES they would prefer to be broadly applied at a local level (Table 4). The answers analysis showed that solar energy and wind power installations on land are highly preferable by the participants. The majority of the participants are negative towards RES installations in the sea (wind power systems in the sea) or the exploitation of its energy (wave/ tidal, small hydroelectric systems). Also, almost all of the participants do not choose at all natural gas or biomass burning to cover energy needs at a broader local level.

Table 4. Preferable RES implementation on a local level

\begin{tabular}{lc}
\hline Forms of RES & Frequency (f) \\
\hline Which form of energy would you prefer to be used at a local level? \\
Solar energy & 12 \\
Wind plants on land & 11 \\
Wind power systems in the sea & 3 \\
Small hydroelectric systems & 3 \\
Wave/tidal systems & 3 \\
Natural gas & 2 \\
Biomass & 2 \\
\hline
\end{tabular}

In order to investigate the participants' views on RES technology applications in public services, facilities and public buildings in their area of responsibility, they were asked to rank the available RES technologies depending on what they believe about the degree of applicability (options: 1: can be absolutely applied, 2: can be considerably applied, 3: cannot possibly applied) (Table 5).

Table 5. Participants' views on RES technology applications in their territories

\begin{tabular}{llll}
\hline \multirow{2}{*}{ RES technologies } & \multicolumn{3}{l}{ Frequency (f) } \\
\cline { 2 - 4 } & $\mathbf{1}$ & $\mathbf{2}$ & $\mathbf{3}$ \\
\hline Bioclimatic architecture & 8 & 3 & 1 \\
Small range solar systems & 7 & 5 & - \\
Wide range solar systems & 6 & 6 & - \\
Photovoltaic systems in buildings & 6 & 6 & - \\
Photovoltaic systems in several areas of the city & 5 & 5 & 2 \\
Wind power systems & 9 & 3 & - \\
Biomass & 2 & 2 & 4 \\
Use of urban waste & 3 & 5 & 4 \\
Geothermal systems & 2 & 4 & 4 \\
Natural gas & 2 & 8 & 2 \\
\hline
\end{tabular}

From the data of Table 5, it is clear that the available RES technologies, such as solar and wind power systems as well as bioclimatic architecture are highly preferable among the participants, who consider them absolutely applicable in practice. Relative to bioclimatic architecture they point out that it could be perfectly applied only in new constructions as for the older ones there are certain urban restructuring restrictions due to the historical value of the buildings. More than half of the respondents believe that small scale solar energy systems are absolutely applicable, while half of them believe the same for large scale solar energy systems, although there is the issue of the location of the installations locally. Typically, large scale systems are those used in factory units, above $10 \mathrm{KW}$ and small scale are household systems up to $10 \mathrm{KW}$. What is more, half of them choose to install photovoltaic systems in buildings, while fewer refer to their broader application in several areas of the urban structure. Respondents' views on RES technologies that have to do with utilization of urban waste, biomass, geothermic and natural gas for energy purposes seem to be divided, as some of them think that they are highly applicable, while others believe that they cannot be applied at all.

\subsection{Views on Policy Planning and Its Application}

In order to study the views of the locally elected representatives on the planning and application of energy policy, certain questions were posed regarding the people in charge of policy planning, the obstacles and difficulties they think are involved in the application of energy measures aiming at energy saving, rational use and RES use and actions to be taken to reduce or overcome such obstacles.

Answers concerning energy policy planners, those in charge of applying techniques and practices related to energy issues showed that all of the participants believe that the State is mainly responsible (government, parliament, ministries). Local government seems to be highly responsible according to the majority of the respondents ( 8 out of 12 ), however opinions are divided because quite a few (4 out of 12) do not agree. Participants recognize partial responsibility to bodies such as the Technical Chamber and the Chamber of Commerce (9 out of 12). Less responsibility is attributed to factory and hotel units by the majority of the participants ( 8 out of 12), while some do not attribute any responsibility to them at all (4 out 12).

Almost all of the respondents state that they come across obstacles and difficulties when applying energy measures for energy saving, rational use of energy and RES use. Answers to a question posed on the types of obstacles and the degree to which they affect the application of measures showed that almost all of the participants (11 out of 12) state that institutional and procedural issues as well as insufficient financing and financial incentives make it impossible to implement measures for a sustainable energy practice. Respondents seem to be divided as to the high cost of application as an obstacle to the implementation of energy efficient practices. Almost half of them (7 out of 12) consider that high cost impedes sustainable energy practices application in contrast to the rest (5out of 12), who believe that the cost does affect application but to a smaller degree. For the majority of the participants (9 out of 12) technical difficulties, 
ignorance of those in charge, of the public or employees in the companies involved, as well as indifference towards the application of energy measures are quite a serious obstacle to their implementation. Half of the people asked (6 out of 12) believe that another important obstacle is the lack of specialized professionals, while the rest ( 6 out of 12) believe that this factor does not affect the implementation of the measures. Nearly one out of three (4 out of 12) states that the fact of non-acceptance of such measures by citizens or company employees is not a serious problem, in contrast to the majority (8 out of 12 ), who think that this is an important factor.

In order to investigate ways to overcome difficulties, which participants themselves refer to as obstacles to the implementation of sustainable energy practices, they were asked to rank a series of actions to be taken according to their importance. From the answers analysis it seems that almost all of the Mayors believe that obstacles could be removed with some absolutely necessary actions concerning institutional issues, such as the simplification of the institutional context, the application of relevant rules and regulations of the State, the adoption of regulations, the financing by the State and the integration of issues of energy saving, rational use of energy and RES use in schools. Their viewpoints on the importance of the information the public should receive from the Mass Media, the State or the local government are divided, as more than half of them ( 8 out of 12) claim that these actions are absolutely necessary, while the rest ( 4 out of 12 ) believe them to be of less importance.

All of the respondents totally agree with the need to plan and apply educational programs both for the citizens and certain social groups, such as politicians, businessmen and employees aiming at the sustainable development on the island of Rhodes and the Dodecanese. For the planning and application of the above programs all of the participants refer to the responsibility of the regional energy agency of the Dodecanese and the Municipalities themselves. Almost everyone believes that the Technical Chamber and the University of the Aegean (11 out of 12) and the Public Power Corporation department in Rhodes (10 out of 12) are responsible. Fewer (9 out of 12) attribute responsibility to the various professionals associations on the island and half of them (6 out of 12) to the institutional primary and secondary education.

\subsection{Existent Energy Policy and Energy Applications for Energy Saving and RES Implementation in Local Government Services}

For the investigation of the aspects of energy policy which is practically applied, the representatives of the local government were asked if there is a person in charge of energy management, if energy application, energy management and action plan studies are being carried out and by whom, if there has ever been set up special support and financial motives policy for the production, transportation and use of electric energy and if there is an attempt to design and apply energy educational programs for the employees in their area of concern.
From the answers analysis it is evident that only in two out of the twelve bodies of the local government of Rhodes there is a designated energy administrator, the first one being in charge of the energy facilities and the second being in charge of the planning of energy management in the services under his jurisdiction. Half of the local government bodies that took part in the present study (6 out of 12) state that there are energy management studies carried out and relevant action plans prepared in the services of their concern. Three of them use the Municipality's technical services and two of them the regional energy agency of the Dodecanese, while one is cooperating with individuals.

Half of the local government bodies ( 6 out of 12) claim that they are designing educational programs for their staff on issues regarding energy saving, rational energy use and RES application, while only two are already implementing such programs.

For the recording of the existing energy practices respondents were asked to choose among several applications that aim at energy saving and rational energy use, as well as RES use and suggest additional ones. The results are presented in Table 6.

Table 6. Energy-saving and RES implementation techniques in buildings and services

\begin{tabular}{ll}
\hline Statements & Frequency (f) \\
\hline $\begin{array}{l}\text { Which of the follow you have applied in the buildings } \\
\text { and services in your territory }\end{array}$ & 11 \\
Turning off the lights when not needed & 9 \\
Turn off electric appliances when not needed) & 8 \\
Appropriate adjustments in cooling and heating & \\
systems according to the season & 8 \\
Control the amount of sunlight that is admitted into & \\
buildings (use of shelters, curtains) & 2 \\
Interventions in the shell of the buildings (use of & 2 \\
insulation materials) & 5 \\
Insulation interventions in the heating systems & 3 \\
Using energy efficient light bulbs & 10 \\
Use of ceiling fans instead of air conditioners & 1 \\
Use of solar water heating systems & 1 \\
RES implementation (photovoltaic system) & 3 \\
RES implementation (geothermal heating system) & \\
Replace energy consuming appliances &
\end{tabular}

From the answers analysis it is clear that almost everyone is taking action against overconsumption in their services such as turning off the lights when not needed, and closing the windows when the air conditioners are on. Most of them ( 9 out of 12) turn off electric appliances when not needed. Two out of three representatives ( 8 out of 12) apply practices that have to do with the cooling and heating of the buildings making the appropriate adjustments according to the season and practices to control the amount of sunlight that is admitted into buildings, such as shelters, curtains and ventilation systems. Interventions in the shell of the buildings that reduce energy waste, such as the use of insulation materials and windows are put into practice by only two of the participants. The same number of representatives, ( 2 out of 12 ), make insulation interventions in the heating system. Fewer than half of the 
participants (5 out of 12) have been using energy efficient light bulbs and even fewer ( 3 out of 12) have replaced energy consuming appliances. The use of ceiling fans instead of air conditioners is limited and only by the minority of the representatives (3 out of 12), while most of them have installed solar water heaters to cover hot water needs. Applications relevant to RES are extremely limited with only one of the municipalities having installed a photovoltaic system in its central building for the production of energy and applied a geothermal heating system in one of its other buildings.

\section{Discussion}

Attitudes of the local authorities are recognized as a crucial factor for energy saving, RES application for energy production locally, as well as for the promotion of the European Union aims regarding the energy issue on the prospect of energy sustainability [3, 17-19]. On the one hand, they are themselves significant energy consumers, in their territories, in the case of public lighting, building and services lighting and transportations. On the other hand, they are responsible for the planning and application of energy policy locally and in addition, they inform and educate citizens affecting their behavior. The present study was carried out in this context and the findings are to be discussed below.

The sustainable management of the environment and environmental issues requires the existence of several factors among which the degree of information and education of the people in charge. Regarding their education on environmental issues, fewer than half of the representatives of the municipalities and the prefecture that took part in the study, have been in some ways relevantly educated during their studies, however not particularly on the energy matter. They show a great interest on the environment and related issues because as they mention they are often informed by several sources, mainly the Media (TV and the press) and the web. The Media and the web are the most important sources of information on the environment for all citizens and especially some social groups (teachers, students) both in Greece and internationally $[16,32]$.

As far as the information on energy issues is concerned it seems that the degree to which they believe they are informed on certain aspects varies. In particular, it seems that the majority of the people asked think that they are adequately informed on energy saving matters, not adequately informed on RES applications and less informed on the rational use of energy. The majority of the respondents derive information on these issues mainly from the web and the press and less from workshops or seminars organized by universities or institutes.

What they consider as the most serious environmental issues are those relevant to energy, such as the production, the sufficiency of electric energy and the exhaustion of natural resources, in contrast to European citizens, who, in their majority, refer to air and water pollution [32].

Even though participants consider the energy issue and especially energy consumption as a modern environmental issue, it seems that they do not recognize the local government as a large energy consumer. On the contrary, they think that hotel industry is energy consuming. There is no doubt that hotels consume large amounts of energy [33-34]. However, the local government is also energy consuming, as its services and its buildings use large amounts of energy for lighting, heating and cooling. There is also energy demand for public lighting and transportations. It should be pointed out that at a European level the main target is to reduce $\mathrm{CO}_{2}$ emissions (related to the use of energy) by $20 \%$ in local communities use and the improvement of energy efficiency by $20 \%$ or more by 2020 [1-3].

The participants are highly aware of energy production in the area of study, Rhodes, Greece, where energy is produced with the use of oil, although some of them believe that lignite is used, a practice applied nationally but not locally [21-22]. Almost everybody knows about the limited use of RES in the production of energy on the island which is a combination of solar and wind power systems.

All of the participants state that the existent energy production system is inefficient, as they claim that it cannot cover the needs on the island, especially during highly touristic seasons. They seem to agree that a second power plant is necessary, along with a broader application of RES. The above findings show that despite they believe that power plants cause environmental problems it is a priority for them to cover energy needs on the island even if that entails the building of a new power unit. Naturally, they refer to the simultaneous broad use of RES for energy production but they have reservations about their efficiency, as they think that they cannot meet the energy needs of the island. They believe that RES could only act as subsidiary means of energy production and that is their main thesis. This particular attitude of the locally elected representatives is contrasted to the European energy policy, which acknowledges the efficiency of RES and aims at raising the energy share of RES by $20 \%$ in the gross final consumption of energy by 2020 [2-4].

The cost seems to influence to a great degree their attitude towards RES applications to cover energy needs. Most of them set the condition that the cost should not exceed the conventional energy production cost that currently exists and few are willing to afford a greater cost. The economic factor seems to act negatively in RES application for local government representatives in other countries as well, like for example in the Czech Republic and America [18]. On the other hand, citizens in countries such as Germany [35] or in other parts of Greece [14] insist on the clean energy from RES regardless of the cost of its production.

The choice of RES as an exclusive means of energy production would be desirable by all of the participants, as they claim that they are environmentally friendly and they reduce greenhouse gases emissions, nevertheless, as already mentioned, they do not believe they are sufficient for the energy needs of the island. In order to deal with energy needs in Rhodes all participants primarily opt for solar energy as it is in abundance. In Rhodes sunshine reaches up to 115 hours monthly and the annual solar radiation is $2000 \mathrm{KWh} / \mathrm{m}^{2}$ 
[36-37]. In order to take advantage of the solar energy they agree upon the installation of small and large scale energy systems, photovoltaic systems in buildings and the town for its lighting.

The option that follows is the creation of wind farms on land, while the idea of wind systems in the sea is turned down because it could devalue the area, which is of major touristic importance. In general, as relevant studies have recorded, citizens' views on wind farms appear divided. Both in Greece and internationally it is observed that a number of citizens support the installation of wind farms, while a number worth mentioning are negative towards it because of several factors, such as socio- economic, or the devaluation of landscape aesthetics [11-12, 14-15, 35, 38].

Respondents' opinions on RES technologies concerning the utilization of urban waste, biomass, geothermic energy and natural gas for energy purposes also seem to be divided. This happens because some of them believe those technologies are quite applicable and others partially or not applicable at all.

Concerning energy policy that elected representatives apply or are willing to apply locally, results are quite interesting. It should be pointed out that the majority of the participants claim that the State (government, parliament, ministries) is mainly responsible for designing the energy policy and applying techniques and practices relative to energy matters. Their views on the responsibility of the local government are divided, as most of them believe that it is crucial, while one out of three does not attribute any responsibility at all.

As far as the implementation of measures on energy saving, rational energy use and RES application is concerned, they state that they come across obstacles and difficulties. As most important they name institutional and procedural issues, insufficient financing and insufficient financial incentives. Technical difficulties, lack of specialized professionals, ignorance, the indifference of those in charge, company employees and citizens are thought to be a great obstacle to the implementation of energy practices. In order to overcome these problems, all of the representatives claim that some actions regarding institutional issues are absolutely necessary, for example the simplification of the institutional context, the application of relevant rules and regulations of the state, the adoption of regulations, State funding and the implementation of issues on energy saving, rational energy use and RES in schools for the education of future citizens. The provision of financial incentives and the reinforcement of the local government by the central state, the governments, are also considered significant by the locally elected representatives in other countries as well [19].

All participants absolutely agree on the need for planning and implementing educational programs both for the citizens and for special social groups, such as politicians, businessmen and company employees aiming at the sustainable energy management in accordance with the objectives of sustainable development on the island. To this direction, they believe that the role of the University of the Aegean, as well as the energy management bodies (Public Power Corporation, Hellas, chambers) is crucial. Despite the great importance they attach to information and education provided on energy issues the realization of such programs for the education of the staff under their administration is not a common practice but a future plan.

In relation to energy saving and the rational use of energy respondents seem to be taking energy austerity measures regarding the reduction of energy consumption by equipment used in their services mainly through actions and practices by the staff on a daily basis (turning off the lights, closing the windows when air conditioners are on, turning off appliances when not needed). What is more, there are certain cooling and heating adjustments made in the buildings according to each season's standards.

Despite their strong support to bioclimatic architecture as a means to deal with the energy issue, there are not any important actions taken, only some practices relative to the control of the amount of sunlight that is admitted into buildings, with shelters, curtains and ventilation systems all of them to a limited extent.

RES applications are almost inexistent, with only one of the municipalities having installed a photovoltaic system in its central building for energy production and used a geothermal heating system in another building it owns. Finally, only a few of the elected representatives have installed solar water heaters to meet hot water needs.

The island of Rhodes is one of the most popular touristic destinations, with more than 2,000,000 visitors annually. Therefore energy demands are high. However, it is necessary to reinforce local authorities for the development of sustainable energy policies. As it becomes evident from the present study the cooperation of institutions and specialized scientists on energy issue with the local government is crucial in order to design and apply an energy policy in a sustainable way. The Mayors' predominant view on the inability to support local energy needs with an energy model based primarily (or even exclusively) on RES should be thoroughly examined and suitable educational tools should be used to reduce resistance to RES implementation in order to support the local system. Education on issues related to RES could influence their overall attitude towards RES at the level of practical possibilities and applications far from theoretical environmentally friendly speculations, as what it is all about is the broad application of RES aiming at the reduction of the serious effects of conventional energy production process.

Education for the environmental issues, including, energy seems to be the most effective tool to promote sustainability. As in [39] quoted:

In order to achieve sustainability, an enormous co-ordination and integration of efforts is required in a number of crucial sectors and rapid and radical change of behaviors and lifestyles, including changing consumption and production patterns. For this, appropriate education and public awareness should be recognized as one of the pillars of sustainability together with legislation, economy and technology. 


\section{Conclusions}

The present study investigates the knowledge and views of the locally elected representatives of Rhodes on production, management and consumption of energy at a local level. Results show that locally elected representatives of Rhodes have the following tendencies:

- They are highly informed on energy production both on the island and in Greece and its effects on the environment.

- They believe that they play a secondary role in the planning and development of energy policy at a local level, as they estimate that energy policy is mainly a matter of the central government.

- They recognize the importance of RES for the production of energy; however they are skeptical about RES efficiency, as they believe they cannot cover the energy needs of the island.

- No RES technologies are being applied in buildings, services or other local facilities in their territories.

- Institutional and procedural issues, as well as insufficient financing incentives constitute serious obstacles to the implementation of energy saving practices and RES applications in their territories.

\section{Acknowledgment}

The authors are thankful to the Mayors of local authorities of Rhodes, Island, Greece, of the period 2010-2014 for their participation in this survey.

\section{References}

[1] European Environmental Agency (2006). Greenhouse gas emission trends and projections in Europe. Report No 9. Copenhagen: EEA

[2] European Commission (2013a). GREEN PAPER. A 2030 framework for climate and energy policies. Brussels: European Commission,

[3] European Commission (2013b). Empowering local and regional authorities to deliver the EU climate and energy objectives. Brussels: European Commission.

[4] European Commission (2010a). LIFE and local authorities Helping regions and municipalities tackle environmental challenges. Belgium: European Union.

[5] Covenant of Mayors. Available at http://www.eumayors.eu/IMG/pdf/covenantofmayors_text_en. pdf

[6] Covenant of Mayors. Available at http://www.simfonodimarxon.eu/ (in Greek).

[7] Skolarikos, M. (2013). (eds). Municipalities in numbers. Athens: The Central Union of Municipalities and Communities (in Greek).

[8] UNESCO (1992). United Nations Conference on Environmental and Development: Agenda 21. Switzerland: Unesco, Chapter 28.
[9] Hungerford, H., Volk T. (1990). Changing learner behavior through environmental education. Journal of Environmental Education, 21 (3): 8-21.

[10] Kollmuss, A., Agyeman, J. (2002). Mind the Gap: why do people act environmentally and what are the barriers to pro-environmental behavior? Environmental Education Research, 8 (3): 239-260.

[11] Ek, K. (2005) Public and private attitudes towards "green" electricity: the case of Swedish wind power. Energy Policy 33(13):1677-1689.

[12] Kaldellis, J.K. (2005). Social attitude towards wind energy applications in Greece. Energy Policy, 33(5): 595-602.

[13] Kaldellis, J.K., Kapsali, M., Kaldelli, E. \& Katsanou, E. (2013). Comparing Recent Views of Public Attitude on Wind Energy, Photovoltaic and Small Hydro Applications. Renewable Energy, 2013 (52): 197-208

[14] Katsaprakakis, D. A. (2012). A review of the environmental and human impacts from wind parks. A case study for the Prefecture of Lasithi, Crete. Renewable and Sustainable Energy Reviews, 16(5): 2850-2863.

[15] Kontogianni, A., Tourkolias, C., Skourtos, M., \& Damigos, D. (2014). Planning globally, protesting locally: Patterns in community perceptions towards the installation of wind farms. Renewable Energy, 66: 170-177.

[16] Liarakou, G., Gavrilakis, C., \& Flouri E. (2009). Secondary School Teachers' Knowledge and Attitudes Towards Renewable Energy Sources. Journal of Science Education and Technology, 2009 (18): 120-129

[17] Busch, H, McCormick, K.(2014). Local power: exploring the motivations of mayors and key success factors for local municipalities to go $100 \%$ renewable energy. Sustainability and Society, 4(5): 1-15.

[18] Frantál, B. (2014). Have Local Government and Public Expectations of Wind Energy Project Benefits Been Met? Implications for Repowering Schemes, Journal of Environmental Policy \& Planning, DOI: 10.1080/1523908X.2014.936583.

[19] Fudge, S., Peters, M., Wade, J. (2012). Locating the agency and influence of local authorities in UK energy governance. Centre for Environmental Strategy, University of Surrey: United Kingdom

[20] Menanteau, F., Finon, D., Lamy, M. L. (2003). Prices versus quantities: Choosing policies for promoting the development of renewable energy. Energy Policy, 31:799-812.

[21] IEA (International Energy Agency), (2007). Key world energy statistics, $1-82$.

[22] Roosa, A. S., (2008), Sustainable Development Handbook, Fairmont Press, Inc.

[23] Rogelj, J., McCollum, D. L, Riah,i K. (2013). The UN's 'Sustainable Energy for All' initiative is Compatible with a Warming Limit of $2^{\circ} \mathrm{C}$. Nature Climate Change, 3: 545-551, doi:10.1038/nclimate 1806 .

[24] EC, European Commission (2010b). EUROPE 2020. A strategy for smart, sustainable and inclusive growth. Belgium: European Union. 
[25] YPEKA, Ministry of Environment, Energy and Climate Change (2014). National action plan on renewable energy sources. Athens: YPEKA (in Greek).

[26] PPCH, Public Power Corporation, Hellas, (2012). Re newable energy sources in non interconnected islands. Fact Sheet for the year 2012. (In Greek).

[27] PPCH, Public Power Corporation, Hellas (2013). Renewable energy sources in non-interconnected islands. Fact Sheet for the year 2013. (In Greek).

[28] HEDNO, Hellenic Electricity Distribution Network Operator (2012). Fact Sheet: electricity power production in non-interconnected islands for the year 2012. (In Greek).

[29] HEDNO, Hellenic Electricity Distribution Network Operator (2013). Fact Sheet: electricity power production in non-interconnected Islands for the year 2013. (In Greek).

[30] HEDNO, Hellenic Electricity Distribution Network Operator (2014). Fact Sheet: electricity power production in non-interconnected Islands for the year 2014. (In Greek.)

[31] Pimenidis, D., Dimitriou, A. \& Fokiali, P. (2013). Local society and energy: Citizens conceptions about the operation of the electrical power plant in Soroni, Rhodes, Greece. In Papavasileiou, V. (Eds). Sustainable local societies: a reality or a Vision (353-374). Rhodes: University of Aegean. Electronic edition. ISBN 978-618-81027-0-5. (In Greek).
[32] EC, European Commission European Commission, (2014). Special Eurobarometer 2014. Attitudes of European citizens towards the environment. EC: European Union

[33] Priyadarsini, R., Xuchao, W., Eang, LS, (2009). A study on energy performance of hotel buildings in Singapore. Energy and Buildings, 41 : 1319-1324

[34] Xuchao, W., Priyadarsini, R., Eang, LS, (2010). Benchmarking energy use and greenhouse gas emissions in Singapore's hotel industry. Energy Policy, 38: 4520-4527

[35] Musall, F. D., \& Kuik, O. (2011). Local acceptance of renewable energy - a case study from southeast Germany. Energy Policy, 39(6): 3252-3260.

[36] HNMS, Hellenic National Meteorological Service (2009). Climate report (In Greek).

[37] Huld T., Müller R., Gambardella A., (2012). A new solar radiation database for estimating PV performance in Europe and Africa. Solar Energy, 86: 1803-1815.

[38] SEI, Sustainable Energy Ireland (2005). Attitudes towards the development of wind farms in Ireland. Renewable Energy, Information Office: Ireland.

[39] UNESCO- EPD, (1997). Declaration of Thessaloniki. UNESCO-EPD97/CONF.401/CLD.2, (article 6). Paris: UNESCO. 